\title{
Pengukuran Kualitas Hidup Pasien Hipertensi di Puskesmas Perumnas I Kota Pontianak yang Menggunakan Antihipertensi melalui EQ5D Questionnaire dan VAS
}

\section{(Measurement of Quality of Life of Hypertension Patients at Puskesmas Perumnas I Pontianak that Use Antihypertension through EQ5D Questionnaire and VAS)}

\author{
M Akib Yuswar, Nara Umillia Purwanti, Winda Zuraida \\ Fakultas Kedokteran Universitas Tanjungpura, Pontianak \\ Jl. Prof. H. Hadari Nawawi, Pontianak, Kalimantan Barat 78124 \\ e-mail: yuswarius2018@gmail.com
}

\begin{abstract}
Hypertension can result a decrease in the quality of life of patients, so that an optimal type of antihypertensive therapy is needed. This study aimed to determine the differences in the quality of life of hypertension patients who use monotherapy drugs and a combination of hypertension in the Perumnas I Pontianak. The study design was observational cross-sectional with a purposive sampling technique, using convertion index of the European Quality of Life 5 Dimensions (EQ5D) Questionnaire and median values of Visual Analog Scale (VAS). As many as 25 out of 102 patients (24.5\%) did not have problem in all five dimensions both monotherapy and a combination with the highest index of EQ5D 1,000. The problematic dimensions were in the dimensions of pain / discomfort (45.1\%), walking/moving (35.3\%), anxiety/depression (29.4\%), usual activities (13.7\%), and personal care (2.9\%). The quality of life which was measured by VAS has a median value of 70 and there was no difference in quality of life between patients receiving antihypertensive monotherapy and combination.
\end{abstract}

Keywords: Hypertension, quality of life, antihypertension, EQ5D, VAS

\begin{abstract}
Abstrak
Hipertensi dapat menyebabkan penurunan kualitas hidup pasien sehingga diperlukan pemberian jenis terapi antihipertensi yang optimal. Penelitian ini bertujuan untuk mengetahui perbedaan kualitas hidup pasien hipertensi yang menggunakan monoterapi dan kombinasi antihipertensi di Puskesmas Perumnas I Pontianak. Desain penelitian adalah observasional cross sectional dengan teknik purposive sampling melalui European Quality Of Life 5 Dimensions (EQ5D) Questionnaire dengan cara mengkonversi skor EQ5D menjadi EQ5D Indeks sedangkan analisis Visual Analog Scale (VAS) menggunakan nilai median. Hasil penelitian dari 102 pasien $(24,5 \%)$, tidak bermasalah pada kelima dimensi baik monoterapi maupun kombinasi dengan EQ5D indeks tertinggi 1,000. Dimensi yang bermasalah pada dimensi rasa sakit/tidak nyaman $(45,1 \%)$, Berjalan/ Bergerak $(35,3 \%)$, Rasa Cemas/ Depresi $(29,4 \%)$, Kegiatan yang biasa dilakukan (13,7\%), Perawatan Diri (2,9\%). Kesimpulan kualitas hidup diukur dengan VAS memiliki nilai median 70 dan tidak ada perbedaan kualitas hidup antara pasien yang mendapat antihipertensi monoterapi maupun kombinasi.
\end{abstract}

Kata kunci: hipertensi, kualitas hidup, antihipertensi, EQ5D, VAS 


\section{Pendahuluan}

Hipertensi dikenal juga dengan sebutan tekanan darah tinggi [1]. Hipertensi terjadi apabila tekanan darah seseorang berada diatas batas normal atau optimal yaitu $120 \mathrm{mmHg}$ untuk sistolik dan $80 \mathrm{mmHg}$ untuk diastolik [2]. Menurut World Health Organization (WHO), penderita hipertensi di seluruh dunia mencapai hampir 1 milyar jiwa atau tepatnya 972 jiwa atau 26,4 \% orang di seluruh dunia mengidap hipertensi. Jumlah penderita hipertensi di negara maju diperkirakan sekitar 333 juta jiwa dan sisanya berada di negara berkembang yang hampir dua kali lipatnya yaitu 639 juta jiwa, termasuk di Indonesia [3]. Data Hasil Riset Kesehatan Dasar tahun 2013 menunjukkan bahwa kejadian hipertensi di Indonesia mencapai angka 25,8\% [4].

Berdasarkan data Dinas Kesehatan Provinsi Kalimantan Barat (2017) menunjukkan bahwa hipertensi menduduki urutan ketiga dari sepuluh besar penyakit yang tertinggi di provinsi Kalimantan Barat yaitu 23.5\% [5], khususnya di Kota Pontianak didapatkan data dari Dinas Kesehatan Kota Pontianak (2017) bahwa hipertensi menduduki urutan kedua dari sepuluh penyakit terbanyak dengan jumlah kasus pada tahun 2017 sebanyak 43.261 kasus [6].

Kualitas hidup adalah persepsi subjektif dari individu terhadap kondisi fisik psikologis, sosial, dan lingkungan dalam kehidupan seharihari yang dialaminya [7]. Berdasarkan penelitian Alfian $\mathrm{R}$, penyakit hipertensi seringkali disertai dengan penyakit komorbid/penyakit penyerta lainnya seperti jantung, ginjal dan stroke sehingga menyebabkan penurunan kualitas hidup seseorang [8]. Kualitas hidup pasien hipertensi yang juga disertai komplikasi dapat mengalami penurunan dalam beberapa aspek fisik, psikologis dan sosial dibandingkan dengan pasien yang tekanan darah normal dan tanpa meminum obat antihipertensi [8].

Pengukuran kualitas hidup pada pasien hipertensi dilakukan dengan mengkaji jenis antihipertensi yang dikonsumsi pada pasien hipertensi [9]. Pengobatan antihipertensi dapat menggunakan obat tunggal (monoterapi) atau dengan kombinasi [10]. Terapi lini pertama pasien baru terdiagnosa hipertensi yaitu diberikan antihipertensi dalam bentuk monoterapi [11], sedangkan pemberian obat antihipertensi dalam bentuk kombinasi tidak bisa dihindari oleh pasien hipertensi yang disertai komplikasi penyakit kardiovaskular lainnya serta dapat menurunkan tekanan darah lebih besar dibandingkan monoterapi antihipertensi [12].

Ada beberapa metode pengukuran kualitas hidup pasien yaitu metode European Quality Of Life 5 Dimensions (EQ5D) dan Visual Analog Scale (VAS) Berkaitan dengan hal itu peneliti tertarik ingin melakukan pengukuran kualitas hidup pasien hipertensi yang menggunakan obat monoterapi atau kombinasi antihipertensi melalui kuisioner dengan metode European Quality Of Life 5 Dimensions (EQ5D) dan Visual Analog Scale (VAS) di Puskesmas Perumnas I kota Pontianak.

\section{Metode Penelitian}

Alat yang digunakan dalam penelitian ini adalah alat tulis, lembar inform consent, lembar pengumpul data kuisioner European of Life 5 Dimensions (EQ-5D) Questionnaire dan Visual Analog Scale (VAS), kalkulator, aplikasi Microsoft Excel dan aplikasi SPSS (Statistical Package for the Social Science) 23. Bahan yang digunakan dalam penelitian ini adalah penderita hipertensi yang mendapat pengobatan monoterapi atau kombinasi antihipertensi di Puskesmas Perumnas I Kota Pontianak.

Desain penelitian yang dilakukan menggunakan metode observasional dengan rancangan potong lintang (cross-sectional study) yang bersifat prospektif. Pengambilan data dilaksanakan di Puskesmas Perumnas I Kota Pontianak pada bulan November 2018 Januari 2019. Kriteria inklusi yaitu pasien yang bersedia untuk mengisi informed consent, kuisioner European of Life 5 Dimensions (EQ5D) Questionnaire dan Visual Analog Scale (VAS), pasien hipertensi yang menjalani pengobatan hipertensi rawat jalan di Puskesmas Perumnas I Kota Pontianak, pasien hipertensi berusia $\geq 18$ tahun, pasien yang menerima resep monoterapi atau kombinasi antihipertensi, pasien yang menerima resep monoterapi antihipertensi sebanyak 51 pasien dan pasien yang menerima resep kombinasi antihipertensi sebanyak 51 pasien sedangkan ktiteria eksklusi yaitu pasien hipertensi yang mengalami buta huruf, pasien yang tidak mengisi kuisioner secara tidak lengkap, pasien yang dirujuk ke rumah sakit, pasien memiliki resep yang rusak atau tidak lengkap.

Penentuan minimal sampel menggunakan rumus Lemeshow, sebagai berikut: 


$$
\mathrm{n}=\frac{\mathrm{Z} \alpha^{2}(P Q)}{\mathrm{d}^{2}}
$$

Keterangan :

$$
\begin{aligned}
& \mathrm{n} \quad=\text { Besar sampel } \\
& \mathrm{Z} \alpha \quad=\text { Nilai baku distribusi normal pada } \alpha \\
& \text { tertentu } \\
& \mathrm{P} \quad=\text { Proporsi prevalensi pasien hipertensi } \\
& \text { di Kota Pontianak }(0,14) \\
& \mathrm{Q} \quad=1-\mathrm{P} \\
& \mathrm{d} \quad=\text { Derajat presisi mutlak } 0,1 \\
& \mathrm{n}=\frac{1,96^{2} \times 0,14(1-0,14)}{0,1^{2}} \\
& n=\frac{3,8416 \times 0,14(0,86)}{0,01} \\
& n=46,2 \text { sampel }
\end{aligned}
$$

Diperoleh sampel minimal sebanyak 46 sampel. Hasil yang diperoleh dilebihkan $10 \%$

\begin{tabular}{|c|c|c|c|}
\hline \multirow{2}{*}{ No } & \multirow{2}{*}{$\begin{array}{c}\text { Karakteristik } \\
\text { Pasien }\end{array}$} & \multicolumn{2}{|c|}{$\mathrm{n}=102$} \\
\hline & & Total & $\%$ \\
\hline \multirow[t]{7}{*}{1} & Usia & & \\
\hline & a. 26-35 tahun & 1 & 0,98 \\
\hline & b. $36-45$ tahun & 3 & 2,94 \\
\hline & c. $46-55$ tahun & 22 & 21,57 \\
\hline & d. $56-65$ tahun & 36 & 35,29 \\
\hline & e. $>65$ tahun & 40 & 39,22 \\
\hline & Total & 102 & \\
\hline \multirow[t]{4}{*}{2} & Jenis Kelamin & & \\
\hline & a. Laki-laki & 26 & 25,49 \\
\hline & b. Perempuan & 76 & 74,51 \\
\hline & Total & 102 & \\
\hline \multirow[t]{8}{*}{3} & Pendidikan & & \\
\hline & a. Tidak tamat & & \\
\hline & SD & 16 & 15,69 \\
\hline & b. Tamat SD & 43 & 42,16 \\
\hline & c. Tamat SLTP & 18 & 17,65 \\
\hline & d. Tamat SLTA & 20 & 19,61 \\
\hline & e. Tamat & & \\
\hline & Diploma & 1 & 0,98 \\
\hline
\end{tabular}
menjadi 51 sampel untuk setiap jenis terapi.

\begin{tabular}{|c|c|c|c|}
\hline & $\begin{array}{l}\text { f. Tamat S1 } \\
\text { Total }\end{array}$ & $\begin{array}{c}4 \\
102\end{array}$ & 3,92 \\
\hline \multirow[t]{5}{*}{4} & Pekerjaan & & \\
\hline & $\begin{array}{l}\text { a. Tidak bekerja/ } \\
\text { IRT/ Pensiunan }\end{array}$ & 78 & 76,47 \\
\hline & $\begin{array}{l}\text { b. Wiraswasta } \\
\text { c. Pegawai }\end{array}$ & 22 & 21,56 \\
\hline & Negeri Sipil & 2 & 1,96 \\
\hline & Total & 102 & \\
\hline
\end{tabular}
Jadi, jadi sampel yang akan digunakan untuk jenis monoterapi dan kombinasi terapi sebanyak 102 sampel.

\section{Hasil}

Hasil karakteristik pasien hipertensi dapat dilihat pada tabel 1.

Tabel 1. Karakteristik Pasien Hipertensi di Puskemas Perumnas I Kota Pontianak
Tabel 2 menunjukkan obat antihipertensi yang diterima pasien pada terapi tunggal/monoterapi.

Table 2. Obat antihipertensi yang diterima pasien pada terapi tunggal/monoterapi

\begin{tabular}{llcc}
\hline No & Golongan obat & Frekuensi & $\begin{array}{c}\text { Persentase } \\
(\%)\end{array}$ \\
\hline 1. & CCB: amlodipin & 47 & 92,16 \\
\hline 2. & $\begin{array}{l}\text { ACE inhibitor: } \\
\text { kaptopril }\end{array}$ & 3 & 5,88 \\
\hline 3. & $\begin{array}{l}\text { Diuretik: } \\
\text { Hidroklorotiazid }\end{array}$ & 1 & 1,96 \\
\hline & Jumlah Pasien & 51 & 100 \\
\hline
\end{tabular}

Tabel 3 menunjukkan obat antihipertensi yang diterima pasien pada terapi kombinasi.

Tabel 3. Obat antihipertensi yang diterima pasien pada terapi kombinasi

\begin{tabular}{llcc}
\hline No & Golongan obat & Frekuensi & $\begin{array}{c}\text { Persentase } \\
(\%)\end{array}$ \\
\hline 1. & $\begin{array}{l}\text { ACE inhibitor: } \\
\text { kaptopril } \\
\text { CCB: amlodipin }\end{array}$ & 13 & 25,49 \\
\hline 2. & $\begin{array}{l}\text { Diuretik: } \\
\text { Hidroklorotiazid } \\
\text { CCB: amlodipin }\end{array}$ & 38 & 74,51 \\
\hline & Jumlah Pasien & 51 & 100 \\
\hline
\end{tabular}

Tabel 4 menunjukkan gambaran kualitas hidup pasien yang menggunakan antihipertensi hasil pengukuran menggunakan indeks EQ5D.

Tabel 4. Kualitas hidup pasien yang menggunakan antihipertensi melalui EQ5D.

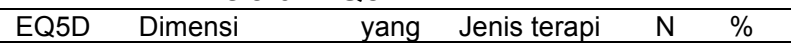




\begin{tabular}{|c|c|c|c|c|c|}
\hline & bermasalah & $\begin{array}{l}\text { Mon } \\
\text { oter } \\
\text { api }\end{array}$ & $\begin{array}{l}\text { Kom } \\
\text { bina } \\
\text { si }\end{array}$ & & \\
\hline$-0,074$ & $\begin{array}{l}\text { Berjalan/Bergerak, } \\
\text { Perawatan diri, } \\
\text { Kegiatan yang biasa } \\
\text { dilakukan, Rasa sakit/ } \\
\text { Tidak nyaman, Rasa } \\
\text { cemas/ Depresi } \\
\text { (Sedih) }\end{array}$ & 0 & 1 & 1 & 1 \\
\hline 0,088 & $\begin{array}{l}\text { Berjalan/Bergerak, } \\
\text { Kegiatan yang biasa } \\
\text { dilakukan, Rasa sakit/ } \\
\text { Tidak nyaman, Rasa } \\
\text { cemas/ Depresi } \\
\text { (Sedih) }\end{array}$ & 0 & 1 & 1 & 1 \\
\hline 0,124 & $\begin{array}{l}\text { Perawatan diri, } \\
\text { Kegiatan yang biasa } \\
\text { dilakukan, Rasa sakit/ } \\
\text { Tidak nyaman }\end{array}$ & 0 & 1 & 1 & 1 \\
\hline 0.157 & $\begin{array}{l}\text { Kegiatan yang biasa } \\
\text { dilakukan, Rasa sakit/ } \\
\text { Tidak nyaman, Rasa } \\
\text { cemas/ Depresi } \\
\text { (Sedih) }\end{array}$ & 1 & 0 & 1 & 1 \\
\hline 0.160 & $\begin{array}{l}\text { Perawatan diri, Rasa } \\
\text { sakit/ Tidak nyaman }\end{array}$ & 0 & 1 & 1 & 1 \\
\hline 0.309 & $\begin{array}{l}\text { Berjalan/Bergerak, } \\
\text { Kegiatan yang biasa } \\
\text { dilakukan, } \\
\text { cemas/ Rasa } \\
\text { (Sedih) }\end{array}$ & 1 & 0 & 1 & 1 \\
\hline 0.345 & $\begin{array}{l}\text { Berjalan/Bergerak, } \\
\text { Rasa cemas/ Depresi } \\
\text { (Sedih) }\end{array}$ & 0 & 1 & 1 & 1 \\
\hline 0.656 & $\begin{array}{l}\text { Berjalan/Bergerak, } \\
\text { Rasa sakit/ Tidak } \\
\text { nyaman, Rasa cemas/ } \\
\text { Depresi (Sedih) }\end{array}$ & 5 & 9 & 14 & $\begin{array}{l}13 . \\
7\end{array}$ \\
\hline 0.691 & $\begin{array}{l}\text { Berjalan/Bergerak, } \\
\text { Kegiatan yang biasa } \\
\text { dilakukan, Rasa sakit/ } \\
\text { Tidak nyaman }\end{array}$ & 1 & 2 & 3 & 2.9 \\
\hline 0.725 & $\begin{array}{l}\text { Rasa sakit/ Tidak } \\
\text { nyaman, Rasa cemas/ } \\
\text { Depresi (Sedih) }\end{array}$ & 4 & 3 & 7 & 6.7 \\
\hline 0.727 & $\begin{array}{l}\text { Berjalan/Bergerak, } \\
\begin{array}{l}\text { Rasa sakit/ Tidak } \\
\text { nyaman }\end{array}\end{array}$ & 4 & 2 & 6 & 5.9 \\
\hline 0.760 & $\begin{array}{l}\text { Kegiatan yang biasa } \\
\text { dilakukan, Rasa sakit/ } \\
\text { Tidak nyaman }\end{array}$ & 1 & 1 & 2 & 1.9 \\
\hline 0.796 & $\begin{array}{l}\text { Rasa sakit/ Tidak } \\
\text { nyaman }\end{array}$ & 12 & 9 & 21 & $\begin{array}{l}20 . \\
6\end{array}$ \\
\hline 0.814 & $\begin{array}{l}\text { Berjalan/Bergerak, } \\
\text { Kegiatan yang biasa } \\
\text { dilakukan }\end{array}$ & 2 & 0 & 2 & 1.9 \\
\hline 0.848 & $\begin{array}{l}\text { Rasa cemas/ Depresi } \\
\text { (Sedih) }\end{array}$ & 4 & 2 & 6 & 5.8 \\
\hline 0.850 & Berjalan/Bergerak & 1 & 6 & 7 & 6.8 \\
\hline 0.883 & $\begin{array}{l}\text { Kegiatan yang biasa } \\
\text { dilakukan }\end{array}$ & 2 & 0 & 2 & 1.9 \\
\hline 1 & Tidak bermasalah & 13 & 12 & 25 & $\begin{array}{l}24 . \\
5\end{array}$ \\
\hline pengu & $\begin{array}{lcr}\text { bel } & 5 & \text { meng } \\
\text { an kualitas hic } \\
\text { lakan antihiperten } \\
\text { si menggunakan VA }\end{array}$ & ambe & $\begin{array}{l}\text { rkan } \\
\text { asien } \\
\text { noterap }\end{array}$ & & \\
\hline
\end{tabular}

e-Journal Pustaka Kesehatan, vol. 7 (no.2), Mei 2019
Tabel 5. Kualitas hidup pasien yang menggunakan antihipertensi monoterapi dan kombinasi menggunakan VAS

\begin{tabular}{lcc}
\hline \multicolumn{1}{c}{ VAS } & \multicolumn{2}{c}{$\begin{array}{c}\text { Obat yang diterima } \\
\text { pasien }\end{array}$} \\
\cline { 2 - 3 } & Monoterapi & Kombinasi \\
\hline $\begin{array}{l}\text { Nilai } \\
\text { terendah }\end{array}$ & 40 & 40 \\
\hline Nilai VAS tertinggi & 95 & 90 \\
\hline Median & 70 & 70 \\
\hline
\end{tabular}

Analisis statistik yang digunakan untuk menganalisis perbedaan kualitas hidup pasien hipertensi yang mendapat monoterapi dan kombinasi adalah uji Mann Whitney seperti tampak pada tabel 6 .

Tabel 6. Hasil uji Mann Whitney

\begin{tabular}{lcc}
\hline & EQ5D & VAS \\
\hline Mann Whitney U & 1153,000 & 1147,500 \\
\hline Wilcoxon W & 2479,000 & 2473,500 \\
\hline$Z$ & $-1,001$ & $-1,062$ \\
\hline $\begin{array}{l}\text { Asymp.Sig. (2- } \\
\text { tailed) }\end{array}$ &, 317 &, 288 \\
\hline
\end{tabular}

Pembahasan

Berdasarkan usia mayoritas pasien yang rentan mengidap penyakit hipertensi didominasi oleh pasien yang berusia $>65$ tahun sebesar $(39,22 \%)$. Berdasarkan penelitian Susanto bahwa semakin bertambahnya usia, kemungkinan seseorang yang menderita hipertensi juga semakin besar. Hal ini terjadi karena pada usia lanjut terjadi penurunan fungsi organ, hilangnya elastisitas jaringan dan terjadinya arterosklerosis [13]. Pasien yang di dapat dari penelitian ini didominasi oleh perempuan sebesar $(74,51 \%)$, hal ini disebabkan tingginya prevalensi pada perempuan sering terjadi setelah mengalami menopause karena pengaruh hormonal yaitu berhentinya produksi hormon esterogen yang menyebabkan tubuh tidak dapat mempertahankan vasodilatasi yang dapat mengontrol tekanan darah serta tidak dapat melindungi pembuluh darah dari kerusakan [14]. Berdasarkan karakteristik pendidikan banyak dijumpai pasien yang tamat SD yaitu sebesar $(42,16 \%)$, Hasil penelitian dari Sumarni bahwa tingkat pendidikan mempengaruhi perilaku 
pasien dalam mengobati penyakit dan memutuskan tindakan terapi yang akan dijalani [15]. Pasien yang didapat dari penelitian ini yang tidak bekerja lebih banyak yaitu 78 pasien $(76,47 \%)$. Berdasarkan penelitian dari Peruntu menyatakan bahawa pekerjaan mempengaruhi aktivitas fisik. Seseorang yang tidak berkerja berisiko menderita hipertensi 22,23 kali dibanding orang yang bekerja 8,95 kali [16]. Hal ini disebabkan kurangnya aktivitas fisik, maka akan berpengaruh terhadap aliran tekanan darah sedangkan jika seseorang yang bekerja dengan melibatkan aktivitas fisik maka dapat terlindungi dari penyakit hipertensi karena dapat memperlancar sirkluasi darah [16].

Pada kelompok terapi tunggal/monoterapi antihipertensi yang paling banyak digunakan adalah golongan CCB yaitu amlodipin sebanyak 92,16 \%. Berdasarkan teori dari Nafrialdi menyatakan bahwa amlodipin golongan CCB telah terbukti efektif dan aman dalam menurunkan tekanan darah serta dapat mengatasi hipertensi darurat karena dosis awalnya yaitu $10 \mathrm{mg}$ yang dapat menurunkan tekanan darah dalam waktu yang singkat [17].

Pada kelompok kombinasi antihipertensi yang paling banyak digunakan yaitu kombinasi antara golongan Diuretik dengan CCB yaitu hidroklorothiazid dan amlodipin (74,51\%). Berdasarkan penelitian dari Setiawati [18], golongan obat CCB dan diuretik efektif dapat mengatasi hipertensi ringan hingga sedang. Namun, kombinasi golongan obat ini yaitu CCB dengan diuretik hanya memberikan efek yang kecil karena obat golongan diuretik hanya meminimalkan efek samping dari golongan obat CCB yaitu edema [18].

Hasil analisa kualitas hidup dari penelitian ini telah didapatkan EQ5D Indeks dari hasil skoring kuisoner EQ5D yang telah dikonversi menggunakan EQ5D Indeks kalkulator. Hasil tersebut menunjukkan bahwa persentase skor European Quality of Life 5 Dimensions (EQ5D) Questionnaire indeks tertinggi sebesar 24,5\% pada dimensi yang tidak bermasalah dengan skor EQ5D indeks sebesar 1 dimana pasien tersebut baik yang mendapatkan monoterapi atau kombinasi antihipertensi tidak memiliki masalah pada kelima dimensi yang terdapat dalam EQ5D.

Hasil analisa tingkat kualitas hidup dalam penelitian ini lalui Visual Analog Scale (VAS) didapatkan sebaran data yang tidak normal yaitu $<0,05$ sehingga analisis data nya menggunakan median. Nilai median VAS pada monoterapi dan kombinasi didapatkan nilai 70. Nilai VAS terendah pada pasien yang mendapatkan monoterapi yaitu 40 dan nilai tertinggi yaitu 95, sedangkan pada pasien yang mendapatkan kombinasi terapi didapatkan nilai terendah yaitu 40 dan nilai tertinggi yaitu 90. Penelitian ini sejalan dengan penelitian yang dilakukan Sari [19]. bahwa nilai median yang didapatkan pada pasien hipertensi yaitu 70. Pembagian kategori skor pada VAS yaitu dibagi menjadi 3 bagian diantaranya sangat baik (81-100), baik (51-80), normal (31-50) dan buruk / sangat buruk (0-30) [20]. Berdasarkan data nilai median VAS didapatkan yaitu 70 artinya kualitas hidup pasien yang mendapatkan monoterapi dan kombinasi memiliki tingkat kualitas hidup yang baik.

Berdasakan hasil analisis SPSS monoterapi signifikansinya 0,317 dan kombinasi signifikansinya 0,288. Dapat disimpulkan secara statistik bahwa tidak ada perbedaan kualitas hidup yang signifikan antara pasien yang mendapatkan monoterapi dan pasien yang mendapatkan kombinasi antihipertensi baik menggunakan EQ5D Indeks maupun menggunakan VAS. Hal ini terjadi karena perbandingan usia yang cukup luas serta penyakit pasien belum tergolong terlalu parah sehingga tidak terlihat perbedaan kualitas hidup pasien yang menggunakan monoterapi dan kombinasi antihipertensi.

\section{Simpulan dan Saran}

Persentase skor EQ5D indeks tertinggi yaitu $24,5 \%$ dan nilai median VAS yaitu 70 serta tidak ada perbedaan kualitas hidup yang signifikan antara pasien yang mendapatkan monoterapi dan pasien yang mendapatkan kombinasi antihipertensi Diharapkan dapat membandingkan obat antihipertensi monoterapi maupun kombinasi yang lebih beragam.

\section{Daftar Pustaka}

[1] Novian,A. Kepatuhan DIIT Pasien Hipertensi. J.Kesehatan Masyarakat. 2013; 9(1): 10.

[2] Palmer,dkk. Tekanan Darah Tinggi. Jakarta: Erlangga.2007.

[3] Yonata A, Satria A. Hipertensi sebagai faktor pencetus terjadinya stroke. Majority. 2016; 5(3): $17-21$.

[4] Badan Penelitian dan Pengembangan Kesehatan Kementerian Kesehatan RI. Riset kesehatan dasar. Jakarta: Badan 
Penelitian dan Pengembangan Kesehatan Kementerian Kesehatan RI; 2013

[5] Dinas Kesehatan Provinsi Kalimantan Barat. Profil kesehatan Kalimantan Barat. Pontianak: Dinas Kesehatan ; 2017.

[6] Dinas Kesehatan Kota Pontianak. Profil kesehatan Kota Pontianak. Pontianak: Dinas Kesehatan ; 2017.

[7] Winahyu KM, Wahyuniati S, Sekarsari R. Hubungan Antara Persepsi Dukungan Sosial dan Kualitas Hidup Lansia dengan Hipertensi di Kota Tanggerang. J. Ilmiah Keperawatan Indonesia. 2017; 1(1): 24-27.

[8] Alfian R, Susanto Yugo, Khadizah S. Kualitas Hidup Pasien Hipertensi Dengan Penyakit Penyerta di Poli Jantung RSUD Ratu Zalecha Martapura. J. Pharmascience. $2017 ; 4(2): 210-218$

[9] Afiani N, Sargowo D, Rini IS. Hubungan Kepatuhan Terapi Terhadap Kualitas Hidup Pasien Dengan Hipertensi Derajat II. J. Kedokteran Brawijaya.2014. 2(1) : 2-9.

[10] Messerli F. Rationale for Combination Therapy In : Clinician's Mmanual On Combination Therapy and Hypertension. Messerli F (Ed). Science Press London. UK ; 2003.

[11]Nurmainah,Fudholi A, Dwiprahasto I. Persistensi Penggunaan Obat Antihipertensi Pada Pasien Hipertensi Rawat Jalan. J. Kesehatan Masyarakat Nasional.2013 ; 8(1) : 13-17.

[12]Sami'un, Pratiwi AD, Rahmawati S. Evaluasi Ketepatan Obat Antihipertensi Pada Pasien Rawat Jalan Dengan Hipertensi Komplikasi. J. Farmasetis. 2018 ; 7(1) ;23-32.
[13]Susanto,H.S.,Udiyono,A.FaktorFaktor Risiko Hipertensi Primer Di Puskesmas Tlogosari Kota Semarang. J.Kesehatan Masyarakat. 2012;1(2) : 315-325.

[14]Barton,M.,Meyer MR.,Postmenopousal hypertension mechanism and therapy. Hypertension. 2009 ; 54 (1).

[15] Sumarni S., Amiruddin R., Leida,, Ida M. Faktor-yang Berhubungan dengan Kualitas Hidup Penderita Hipertensi di Wilayah Kerja Puskesmas Segeri. J. Unhas. 2015.

[16] Peruntu OL.,Rumagit FA., Kures GS. Hubungan Aktivitas Fisik dan Hipertensi pada pegawai di wilayah Kecamatan Tomohon Utara. Gizido. 2015; 7 (1).

[17]Nafrialdi. Antihipertensi Dalam Farmakologi dan Terapi Edisi 5. Jakarta: Departemen Farmakologi dan Terapeutik, Fakultas Kedokteran Universitas Indonesia; 2008.

[18]Setiawati A, Bustami ZS. Antihipertensi Farmakologi dan Terapi Edisi 4. Jakarta: Gaya Baru; 1998.

[19] Sari A, Lolita, Fauzia. Pengukuran kualitas hidup pasien hipertensi di Puskesmas Mergangsan Yogyakarta menggunakan European Quality of Life 5 Dimensions (EQ5D) Questionnaire dan Visual Analog Scale (VAS). Jurnal Ibnu Sina 2017 2(1): 1 - 12.

[20] Monteiro AL, Pereira CCA, Souza IAG. Assessment of quality of life using the EQ5D-3L instrument for hospitalized patients with femoral fracture in Brazil. J. .Health and Quality of Life Outcomes. 2018; 16:194. 